\title{
Load compensation for single phase system using series active filter
}

\author{
Kamala Kant Mishra ${ }^{1}$, Rajesh Gupta ${ }^{2}$ \\ ${ }^{1 *}$ Department of Electrical and Electronics Engineering, Kanpur Institute of Technology Kanpur, INDIA \\ ${ }^{2}$ Department of Electrical Engineering, Motilal Nehru National Institute of Technology Allahabad, INDIA \\ e-mail: kk_kit@rediffmail.com,rajeshgupta310@rediffmail.com.Tel +91-512-2410093,98 Fax.+91-512-2410093
}

\begin{abstract}
The exponentially rising application of power electronics based appliances in Domestic Consumer Voltage Distribution System (DCVDS) has enhanced power quality problems even at the lowest voltage level in distribution system. Starting from transmission system to low voltage distribution system, quite a good number of series active filters has been designed with a limited emphasis on single phase system as no imposition has been made by governing bodies/standards at international level. In this paper a new control strategy for series active filter has been proposed for improvement of power quality problems in single phase system. Since the non linear loads in the system comprises of both voltage source harmonic and current source harmonic loads and the dominancy of each type of load varies from time to time, the non linear load ranging from voltage source type harmonic load (VSHL) dominant to current source type harmonic load (CSHL) dominant has been taken up for study. The proposed series active filter has shown better power quality improvement even with variation of non linear load from voltage source harmonic load dominant to current source harmonic dominant. The power quality improvement has been shown through simulation results using EMTDC/PSCAD.
\end{abstract}

Keywords: Active power filter (APF), current source type of harmonic load (CSHL), domestic consumer voltage distribution system (DCVDS), point of common coupling (PCC), total harmonic distortion (THD), voltage source type of harmonic load (VSHL).

\section{Introduction}

In the last one decade, the economic growth in India has improved the life style of an average Indian. The rising demand of quantity as well as quality power in low voltage distribution system especially by domestic consumer has increased. The apparatus used in single phase are mainly electronically operated and controlled. With use of switched mode operation of such apparatus, the non linear nature of current drawn by such loads, e.g., compact fluorescent lamp (CFL), personal computer (PC), uninterrupted power supply (UPS), etc., has changed the quality of power available to the end user. Even at the domestic consumer end, the loads may be varying from time to time switching over from voltage source harmonic load dominant to current source dominant harmonic loads.

The harmonic creating loads are causing serious power quality problems in low voltage distribution systems. The conventional solution to overcome these problems is the use of tuned passive filters. However, these passive filters can only control a particular frequency to which it is tuned, hence restricted in its application. Other drawbacks are dependency on system impedance, overloading, series and parallel resonance, etc. (Salmerón and Litrán, 2010). Alternative solution to this problem was brought into the light with introduction of active power filters (APFs) by the end of 1980. The operating loss and cost of active filters are less than the passive filters (Akagi, 2005). Lots of work has been done since then on active filters on three phase systems. Various forms of active filters depending upon the construction, configuration and control strategy have been developed in past. Out of these, active filters with parallel passive filters are more common in applications (Salmerón and Litrán, 2010; Akagi, .2005; Ghosh and Ledwich, 2002; Dixon et. al., 1997; Pomilio and Deckmann, 2007; Morán, et al.,1997; Ghosh et al., 2004; Lee .et al., 2004; Ribeiro and Barbi, 2006; Salehifar and Shoulaie, 2007; Kumar and Nagaraju, 2007; Boonchiam. and Mithulananthan, 2008; Benachaiba and Ferdi, 2008; Jazayeri and Abdollahzadeh, 2009; Nemati et al., 2009; Tiwari and Gupta, 2010; Omar and Rahim, 
2010). Single phase active filters could attract less attention than three phase due to its low power levels. However, with increase in power capacity in single phase applications, the researchers are now getting attracted towards development of single phase active power filters (Haque, 2002; Tarnini.,2009; Khadkikar et. al., 2008; Chowdary and Kumar, 2008; Cirrincione et. al., 2009; Mishra and Gupta, 2009; Singh et al.,1999).

Number of control techniques has been developed to obtain control signal for active filters. In one of the technique, APF generates voltage similar but opposition to load harmonic voltage. In another technique, the voltage generated by APF is proportional to the source current harmonics. However, appropriate value of proportionality constant $k$ could not be fixed. Theoretically, $k$ should be high but the infinite value makes the control difficult. Lower value of $k$ keeps the system stability. Also, it tends to make compensation dependent upon passive filter and source impedance (Salmerón and Litrán, 2010).

This paper presents a new technique for series active power filters. The active filter is connected between source and load without any passive filter. The control signal for APF is obtained by separation of reactive and harmonic current from the source current and is multiplied by proportionality constant $k$ to generate reference voltage. The injected voltage is then compared with reference voltage. Hysteresis band method of control is used to track the reference voltage. This method is suitable for VSHL, CSHL, and combination of both, supplied from either distorted source voltage or ideal source voltage.

\section{Layout of DCVDS}

2.1 Classification of distribution system: With the variety of loads in the distribution system ranging from domestic use to commercial applications, there is a need to classify distribution system based upon the loads. The new classification proposed in (Mishra and Gupta, 2009) has been considered here. The suitability of series active filter for domestic consumer voltage distribution system (DCVDS) has been taken up for study. A simple layout of DCVDS is shown in Fig.1. The voltage $v_{s}$ is the voltage source considered at the input of the distribution transformer $T_{1}$. The feeder impedance $Z_{L}$ consists of inductance and resistance. $L_{1}, L_{2}, \ldots \ldots L_{n}$ are various application based loads connected at the PCC.

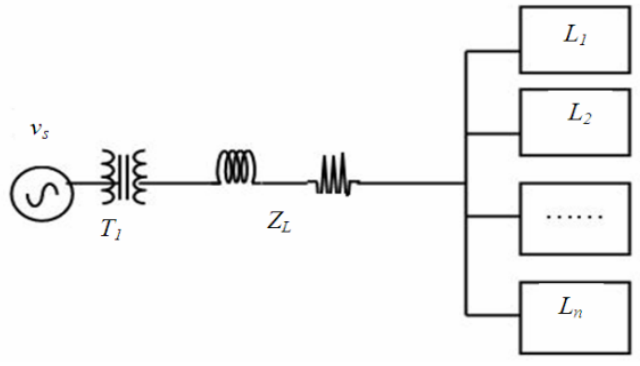

Figure 1. Domestic Consumer voltage distribution system

\subsection{Domestic Consumer voltage distribution system (DCVDS)}

2.2.1 Source: The single phase output of $11 \mathrm{kV} / 440 \mathrm{~V}$ distribution transformer is taken up as a single phase source for the DCVDS. The source voltage may be distorted. Therefore, both ideal as well as distorted source has been taken up for study.

2.2.2 Feeder: As per IEEE 519-1992, typically the line inductance per phase on three-phase ac line (for $<600 \mathrm{~V}$ ) can be considered to be about $1 \mu \mathrm{H} / \mathrm{m}$. The distribution line is considered to be $1 \mathrm{~km}$.

2.2.3 Loads: The various loads in DCVDS may be linear as well as non linear. The non linear loads present in DCVDS are classified into two main categories as current source harmonic loads and voltage source harmonic loads.

o Current source harmonic loads: The appliances using thyristor converters are the current source type harmonic load. The harmonics are generated from the switching operation. The loads falling under such category in DCVDS are motor drives, transformers, air conditioning devices, refrigerator, etc.

o Voltage source harmonic loads: The voltage source type harmonic loads are having diode rectifier with smoothing capacitor in their output circuit. The harmonic amplitude of these loads is highly affected by the impedance of the ac side. Such loads are more common in DCVDS. The loads falling under this category are computers, electronic lamp ballasts, compact fluorescent lamp (CFL), video monitors, television (TV) sets, etc. (Peng, 1998). 


\section{Series active filter}

\subsection{Construction}

The series active filter is placed between ac source and the harmonics producing load. It forces the source current to become sinusoidal. In other words, the series active filter presents high impedance to the harmonic current of the load to flow from the ac source and vice versa. It comprises of:

o Voltage source converter

o DC energy storage

o AC filter circuit

A typical series active filter is shown in Figure 2. The voltage source inverter (VSI) with an input dc source $V_{d c}$, injects the voltage $v_{s d a}$ between the terminals $v_{t a}$ and $v_{l a}$. The voltage $v_{t a}$ is the voltage of the node at which source and the filter is connected and $v_{l a}$ is the voltage of the node at which the filter and load is connected. The dc energy storage may be large capacitors, battery bank, super conducting coils, fly wheels and fuel cells. The filter is connected through a transformer with a leakage resistance and reactance, represented by $R_{T}$ and $L_{T}$, respectively. The currents $i_{s}, i_{s e}$ and $i_{l}$ are the source current, series filter current and load current respectively.

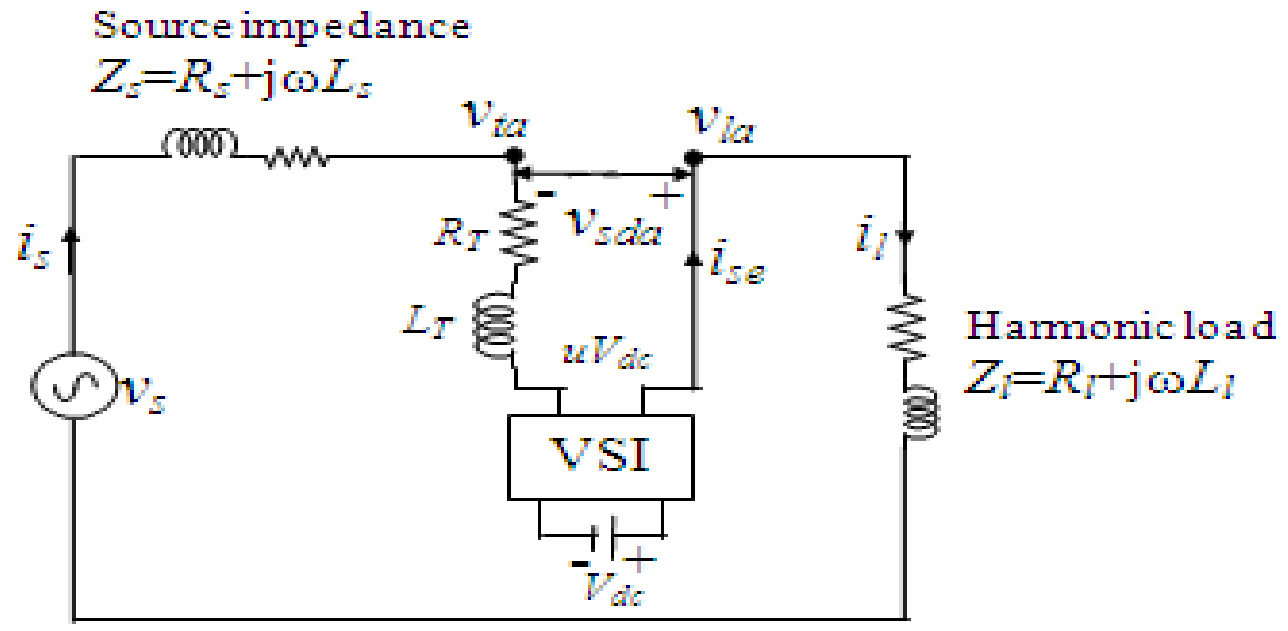

Figure 2. A typical series active filter connected distribution system.

\subsection{Control Strategy}

One of the method used for generation of reference voltage is discussed below. The harmonic and reactive current drawn by the load is extracted from the load current is given below (Ghosh and Ledwich, 2002).

$$
i_{\text {comp }}=i_{l}-\frac{\sqrt{2} P_{a v} \sin \omega t}{V_{r m s}}
$$

where, $P_{a v}$ is the average real power drawn by the load, $i_{l}$ is the load current and $V_{r m s}$ is rms load bus voltage. Equation (1) can also be written as

$$
i_{\text {comp }}=i_{h}+i_{r}
$$

where, $i_{h}$ and $i_{r}$ are the harmonic and reactive components of the load current. Now, the voltage injected by the series active power filter is proportional to the harmonic and reactive component of load current, i.e.,

$$
v_{\text {cfref }}=k * i_{\text {comp }}
$$

where, $k$ is the proportionality constant. Under such a condition, the source current supplies only the active part of the load current and hence becomes sinusoidal. The voltage error $v_{e r r}$ is defined as the difference of the injected voltage $v_{s d a}$ and the reference voltage $v_{\text {sdaref, }}$ i.e.,

$$
v_{\text {err }}=v_{\text {sdaref }}-v_{\text {sda }}
$$


The proposed control strategy is shown in Figure. 3. Where, $P_{\text {inst }}$ and $P_{a v}$ are the instantaneous and average power drawn by the load respectively.

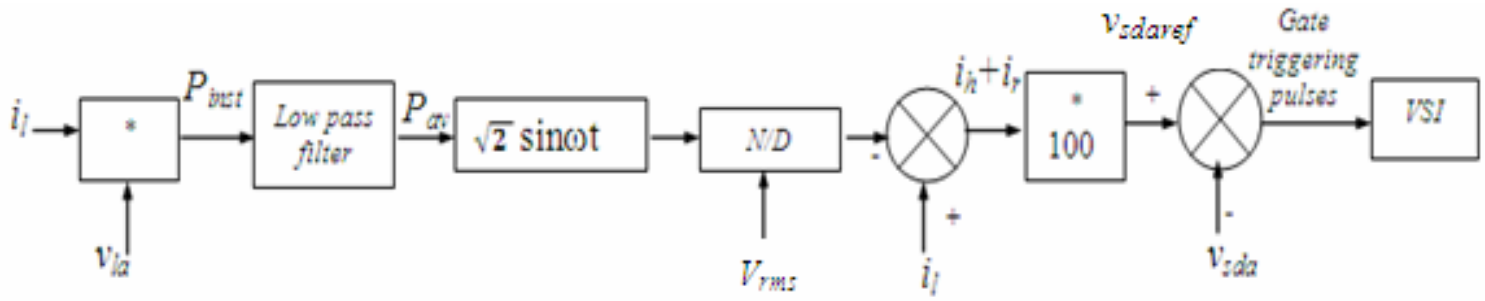

Figure 3, Proposed control strategy for series active filter.

\subsection{Operation}

\subsubsection{For harmonic current source:}

Figure. 2 shows the basic principle of operation of series active filter. The series filter is controlled so as to satisfy the following relation.

$$
v_{\text {sda }}=K G i_{\mathrm{s}}
$$

where, $G$ is the equivalent transfer function of the detection circuit of the harmonic current including delay time of the control circuit. The transfer function $G$ is supposed to be zero at fundamental frequency, i.e., $|G|_{f}=0$, and equal to 1 at harmonic frequency, i.e., $|G|_{h}=1$. The dimension of the gain $K$ is in ohm. The source current $i_{s}$ is given by (Peng, 1998).

$$
i_{s}=\frac{Z_{l} \cdot i_{l}}{Z_{s}+Z_{l}+K G}+\frac{v_{s}}{Z_{s}+Z_{l}+K G}
$$

where, $Z_{l}$ and $Z_{s}$ are the load and source impedances respectively. The currents $i_{l}$ and $i_{s}$ are load and source currents, respectively, and $v_{s}$ is the source voltage. The component of ac source voltage at the harmonic frequency $v_{s h}$ is much smaller than the load current at the harmonic frequency. Therefore, if the following is satisfied,

$$
K>>\mid Z_{l_{\mathrm{h}}} \text { and } K>>\left|Z_{s}+Z_{l}\right|_{\mathrm{h}}
$$

Then we have,

$$
\begin{aligned}
& v_{s d a} \approx Z_{l} i_{l h}+v_{s h} \\
& \text { and } i_{s}=0
\end{aligned}
$$

Thus (3) gives the condition for the series active power filter to compensate for a harmonic current. The other requirement being $K$ should be large and load impedance $\left|Z_{l}\right|_{h}$ should be small for harmonics. But for a conventional phase controlled thyristor rectifier, which is a current source type of harmonic load, $Z_{l}$ is close to infinity; therefore (3) cannot be satisfied. Hence, the series active filter cannot compensate for a current source type of harmonic load, theoretically. However, if a parallel passive filter is connected with thyristor rectifier, then $Z_{l}$ can become very small and (3) is satisfied (Peng, 1998).

\subsubsection{For harmonic voltage source:}

When the load is voltage source type, then it can be represented by a Thevenin's equivalent, i.e., a voltage source $v_{l}$ with an impedance $Z_{l}$. The series active power filter is controlled so as to satisfy (1) and the following can be re-written as

$$
v_{s d a}=K G i_{s}
$$

The source current becomes,

$$
i_{s}=\frac{v_{s}-v_{l}}{Z_{s}+Z_{l}+K G}
$$

Now, when $K>>1 \mathrm{pu}$, then the following can be obtained.

$$
\begin{aligned}
& i_{s} \approx 0 \\
& \text { and } v_{\text {sda }} \approx v_{s h}+v_{l h}
\end{aligned}
$$


Equation (11) is the desired condition for the series active power filter to compensate harmonic voltage source type of load. If $v_{s h}$ is relatively small and if $|1-G|<<1$ is satisfied, the source current becomes sinusoidal even if $K=1 \mathrm{pu}$ (Peng, 1998).

\section{Simulation results}

The details of source and feeder data are given in Table 1. The load comprises of voltage as well as current source type of harmonic loads. The loads are considered domestic consumer types like refrigerator, PC with UPS, television with set up box, CFL etc. The dominancy of load varies from voltage source type of harmonic load to current source type of harmonic load. The capacity of load lies between $2 \mathrm{~kW}$ to $10 \mathrm{~kW}$. The details of load and series active filter are given in Table 2 and 3, respectively.

Table 1, Source and feeder data

\begin{tabular}{|l|l|}
\hline \multicolumn{1}{|c|}{ Source and feeder } & \\
\hline Ideal source & 230V single phase, $50 \mathrm{~Hz}$ \\
\hline Distorted Voltage Source & Voltage THD $=11.89 \%$ \\
\hline Non stiff feeder & $\mathrm{L}=0.001 \mathrm{H}, \mathrm{R}=0$ \\
\hline
\end{tabular}

Table 2, Characteristics of loads

\begin{tabular}{|l|l|}
\hline \multicolumn{1}{|c|}{ Loads } & \multicolumn{1}{c|}{ Specifications } \\
\hline $\begin{array}{l}\text { Current source type harmonic } \\
\text { load }\end{array}$ & $\begin{array}{l}\text { A bridge rectifier with resistance(R) and inductor }(\mathrm{L}) \text { in series in the output } \\
\text { circuit. } \\
1 \leq \mathrm{R} \leq 30 \Omega \\
1 \leq \mathrm{L} \leq 10\end{array}$ \\
\hline $\begin{array}{l}\text { Voltage source type } \\
\text { harmonic load }\end{array}$ & $\begin{array}{l}\text { A bridge rectifier with resistance(R) and capacitor }(\mathrm{C}) \text { of } 500 \mu \mathrm{F} \text { in parallel in the } \\
\text { output circuit. The ac side of the rectifier is connected in series with a smoothing } \\
\text { inductor of } 0.0005 \mathrm{H} . \\
3 \leq \mathrm{R} \leq 70 \Omega\end{array}$ \\
\hline
\end{tabular}

Table 3, Series active power filter data

\begin{tabular}{|l|l|}
\hline \multicolumn{1}{|c|}{ Active filter components } & \multicolumn{1}{c|}{ Specifications } \\
\hline DC link voltage & $350 \mathrm{~V}$ \\
\hline Voltage source inverter & A PWM inverter with snubber circuit enabled for IGBT switch. \\
\hline $\begin{array}{l}\text { Filter impedance in output circuit } \\
\text { of VSI }\end{array}$ & $\mathrm{L}=0.01 \mathrm{H}, \mathrm{R}=1 \Omega$ \\
\hline
\end{tabular}

Based upon the parameters given in Table 1, 2 and 3, the simulation circuit is drawn in PSCAD. A typical circuit with a combination of VSHL and CSHL in shown in Figure 4. 


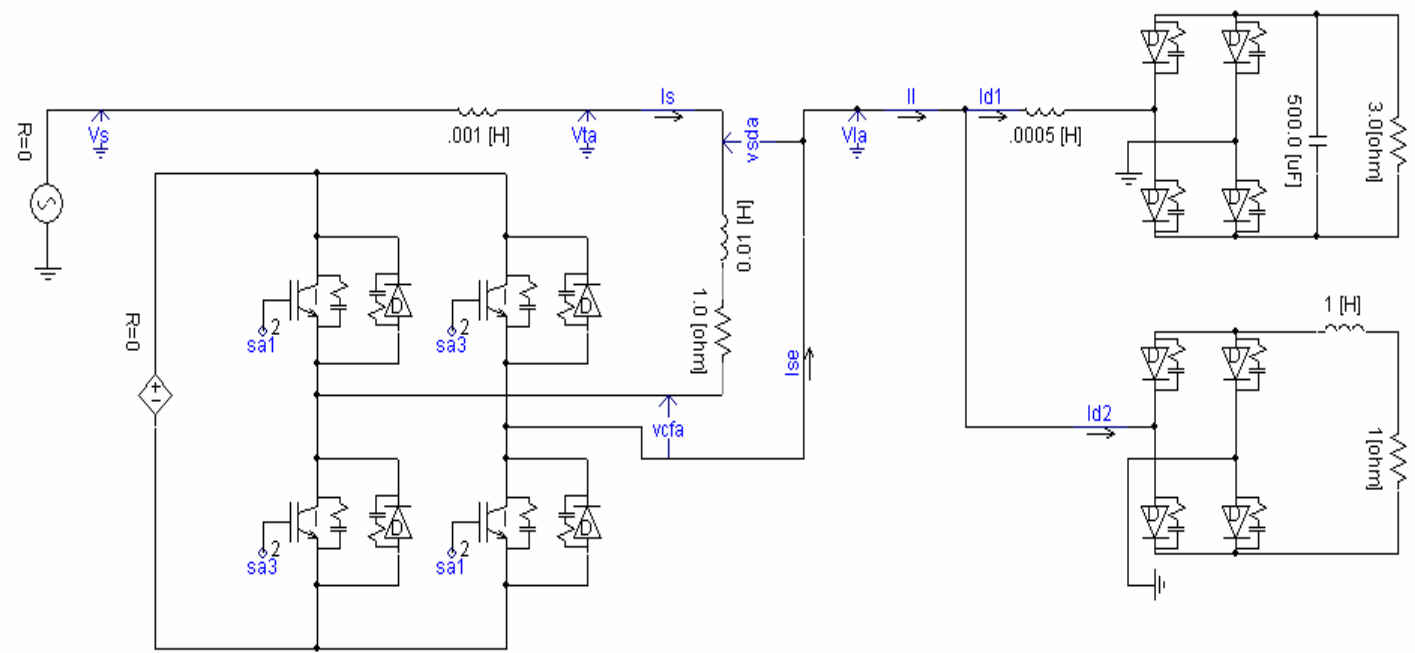

Figure 4, A typical simulation circuit of series active filter connected with VSHL and CSHL.

\subsection{Ideal voltage source}

The voltage source is considered sinusoidal and free from any harmonic. The load with a combination of VSHL and CSHL, varies from $2 \mathrm{~kW}$ to $10 \mathrm{~kW}$ and it was observed that the series active filter offers high impedance to the flow of harmonic current through the line, resulting in flow of only real part of load current from the source. The variation in load current is obtained by varying resistances of both type of harmonic loads.

4.1.1 Case 1. VSHL dominant load: In this case, the load is VSHL dominant. The load current is found to be 23.6 Amp. The ratio of current drawn by VSHL and CSHL is 2.49. Simulation results for this case are shown in Figure 5.

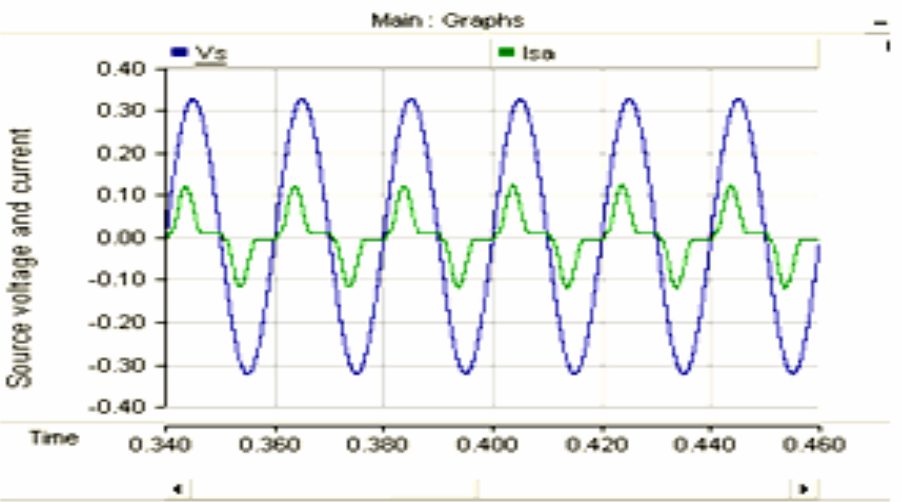

(a)

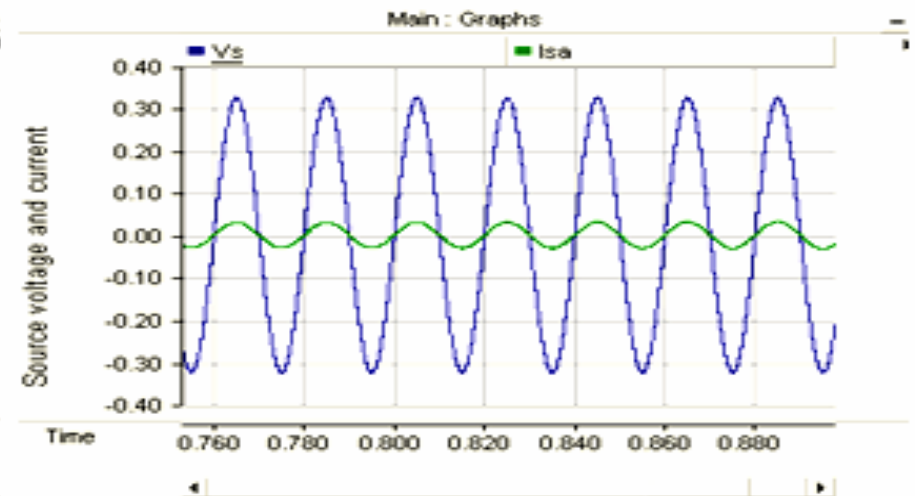

(b)

Figure. 5, Source voltage and current, (a) uncompensated, (b) compensated with series active filter.

The voltage injected in the series circuit is proportional to the sum of harmonic and reactive current drawn by the load. The reference injected voltage $v_{\text {sdaref }}$ (shown as $v_{\text {ref }}$ in all plots ), injected voltage $v_{\text {sda }}$ (shown as $v_{\text {sda }}$ in all plots) and error voltage, $v_{\text {err }}$ (shown as $\mathrm{v}_{\text {err }}$ in all plots) are shown in Figure 6. The reference tracking is performed using hysteresis control method. 




Figure. 6, Tracking characteristics for case1 showing reference, injected and error voltage.

4.1.2 Case 2. CSHL dominant loads: In this case, the non linear load is CSHL dominant. The load current is 31 Amp. The ratio of current drawn by the VSHL and CSHL is 0.8235 . Simulation results for the this case is shown in Figure 7 . The reference $\left(v_{r e f}\right)$, injected $\left(v_{s d a}\right)$ and error voltage $\left(v_{e r r}\right)$, in this case are shown in Figure 8.

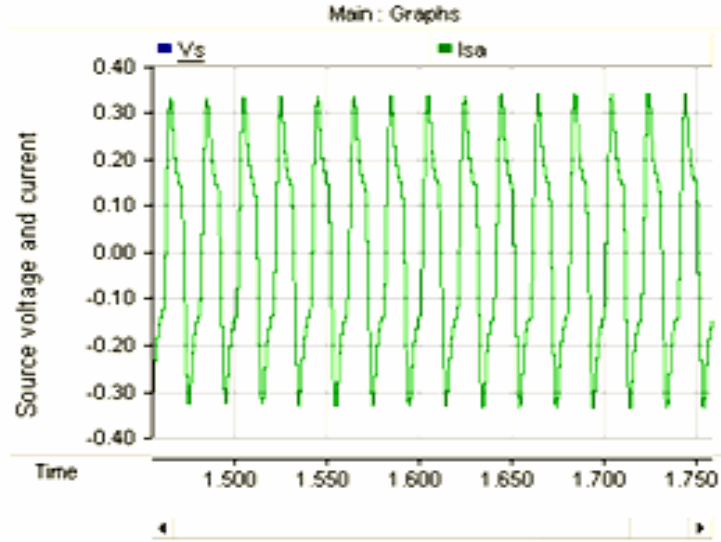

(a)

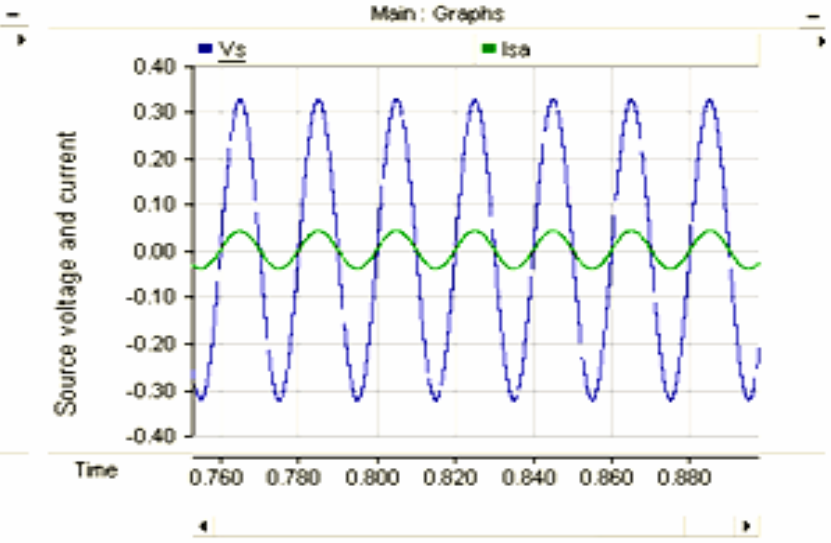

(b)

Figure 7, Source voltage and current, (a) uncompensated system showing source current, (b) source voltage and current when system is compensated with series active filter.

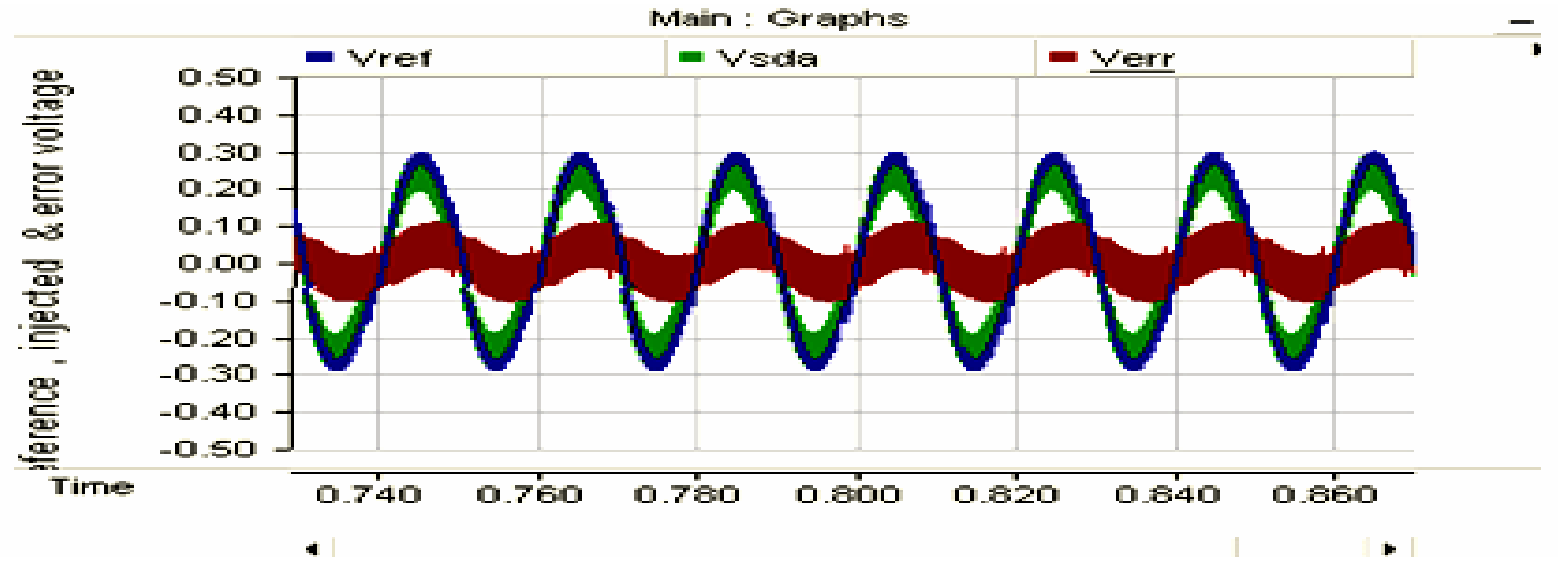

Figure 8, Tracking characteristics for case 2 showing reference, injected and error voltage. 


\subsection{Harmonic source voltage}

The source at the output of the distribution transformer is considered non-ideal and contains harmonics. It results into the distorted source voltage with voltage THD of $11.89 \%$ as given in Table 1 . The load is again varied from VSHL dominant to CSHL dominant, with the variation from $2 \mathrm{~kW}$ to $10 \mathrm{~kW}$.

4.2.1 Case 3. VSHL dominant loads: In this case, the source voltage and the source current was found to be distorted as shown in Figure 9(a) and (b). The load is VSHL dominant. The load current is $20 \mathrm{Amp}$ and the ratio of current drawn by VSHL to CSHL is 2.33. When compensated with series active filter, the source voltage and current becomes sinusoidal, as the desired condition for series active filter to compensate for harmonic voltage source given by equation (11). The compensated system with sinusoidal source voltage and current are shown in Figure 9(c) and (d). The traking charateristics is shown in Figure 10.
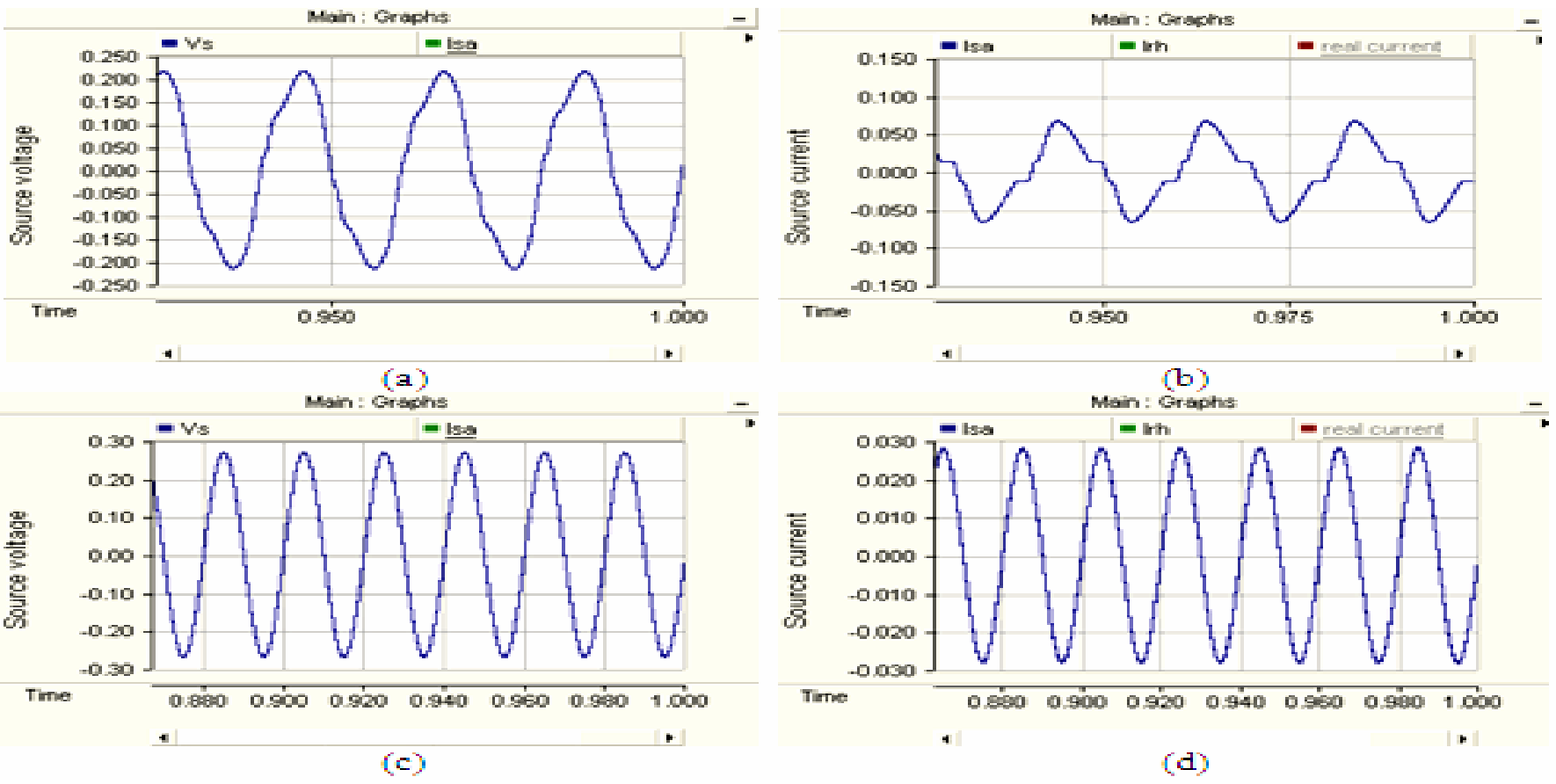

Figure 9, Source voltage and current, (a) uncompensated voltage, (b) uncompensated current, (c) compensated voltage and (d) compensated current using series active filter.

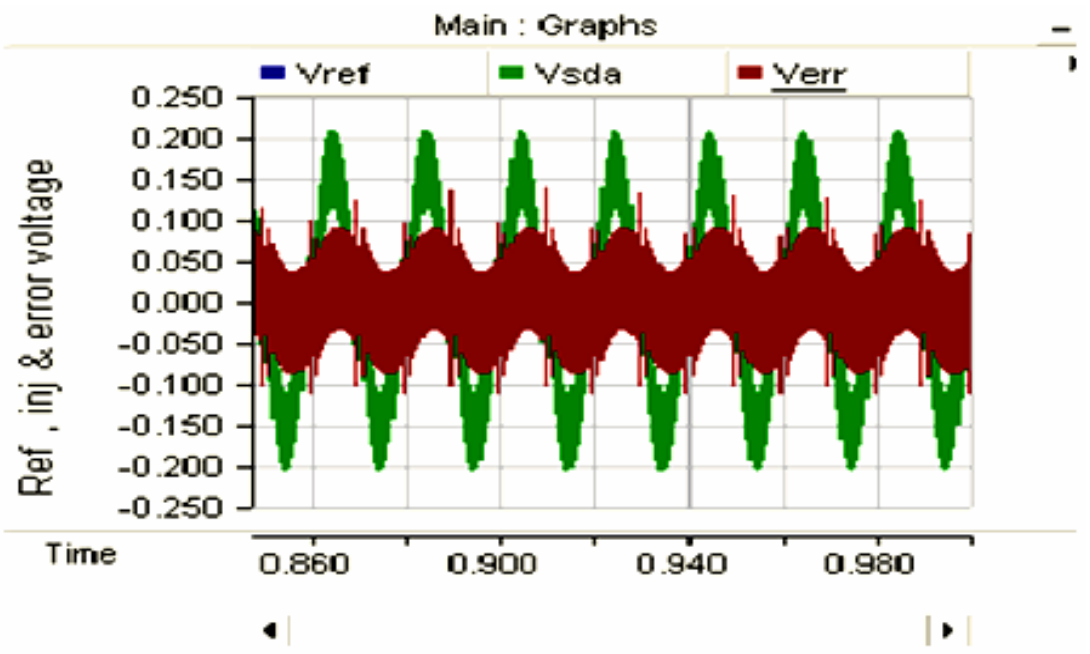

Figure 10, Tracking characteristics for case 3 showing reference, injected and error voltage. 
4.2.2 Case 4. CSHLdominant loads: In this case, the load is varied from VSHL dominant to CSHL dominant. The load current is $19 \mathrm{Amp}$ with the ratio of VSHL to CSHL current 0.38 . The uncompensated system with source voltage and current is shown in Figure.11(a) and (b). While the compensated system's source voltage and current is shown in Figure 11(c) and (d). The traking of reference voltage by injected voltage along with error voltage is shown in Figure 12. It is found that even the source voltage is distorted but with the use of series active filter, the source voltage and current becomes sinusoidal.
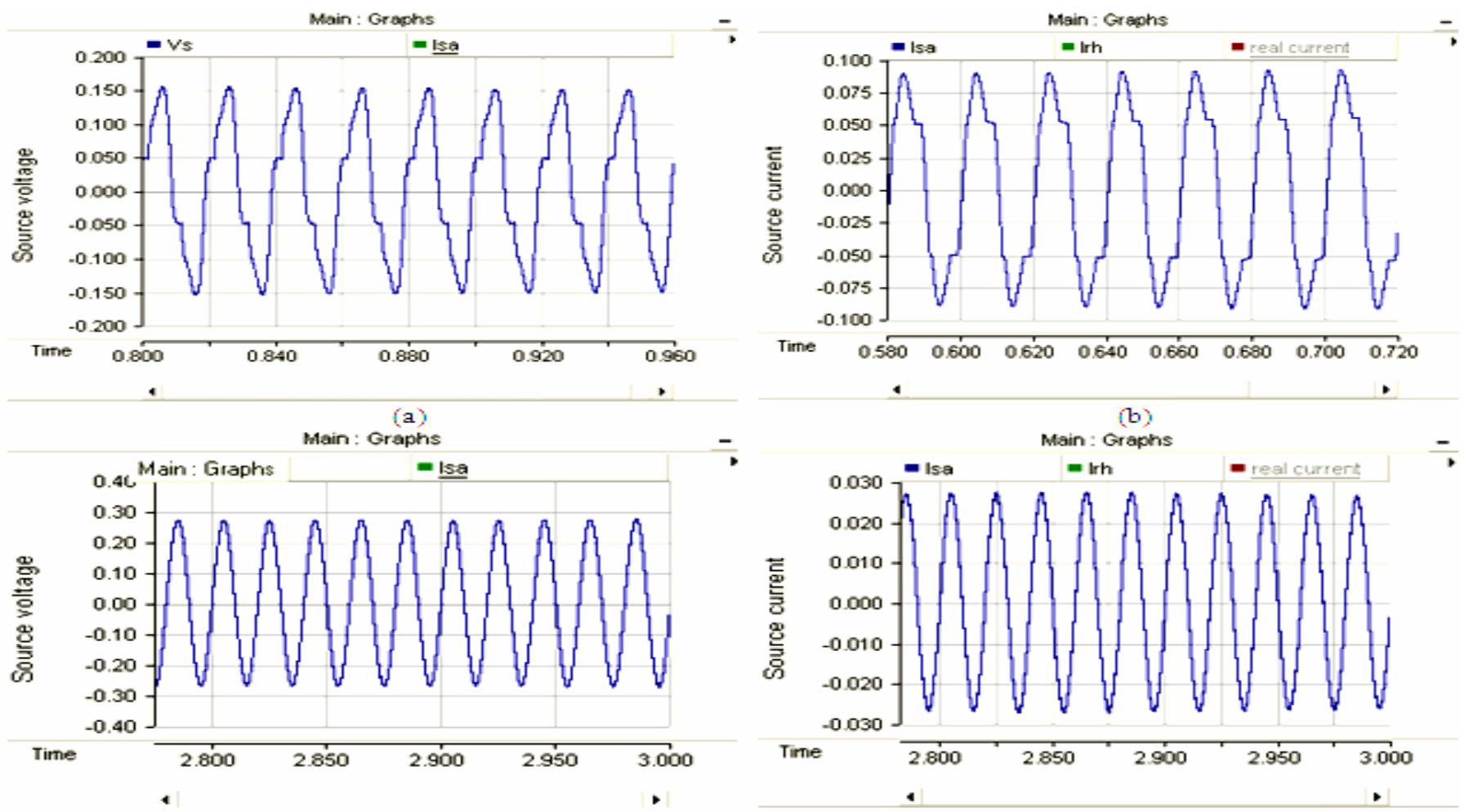

(c)

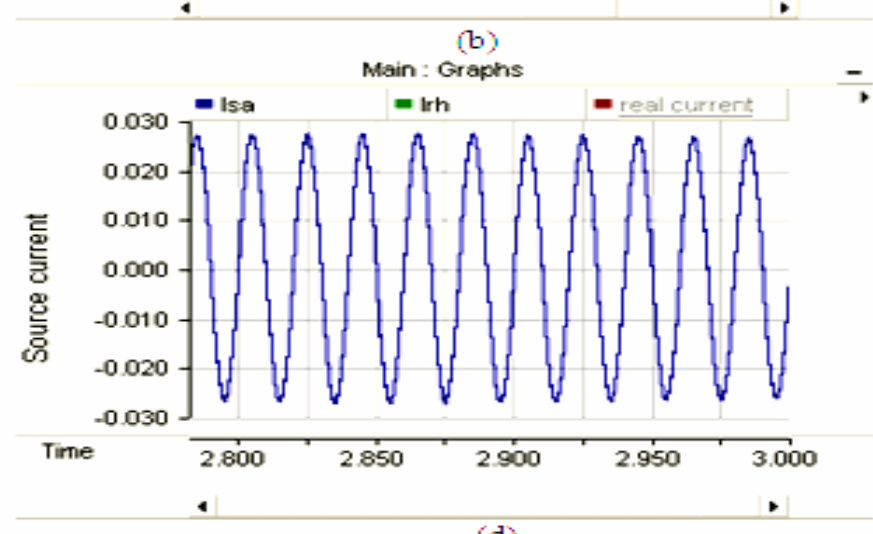

(d)

Figure 11, Source voltage and current, (a) uncompensated voltage (b) uncompensated current, (c) compensated voltage, (d) compensated current using series active filter.

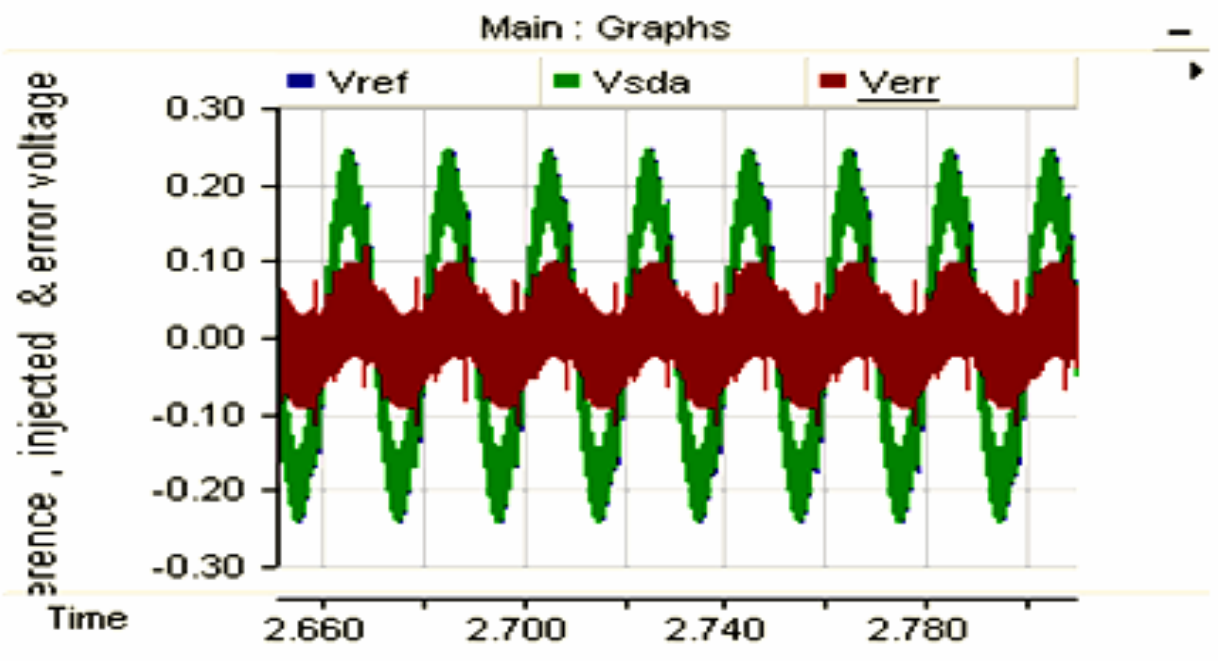

Figure 12, Tracking characteristics for case 4 showing reference, injected and error voltage.

\section{Conclusion}

In this paper, a new and simple control strategy for single phase series active filter has been proposed. The active filter does not use any parallel passive filter and interfacing capacitor. It injects series voltage proportional to the sum of harmonic and reactive current drawn by the non linear load. The simulation results shows usefulness of this filter. The filter is suitable for load variation 
from $2 \mathrm{~kW}$ to $10 \mathrm{~kW}$ with ideal source as well as distorted source. In each case, the source current becomes sinusoidal after compensation.

\section{References}

Akagi H., 2005. Active Harmonic Filters. Proc. IEEE, vol. 93, no.12, pp 2128-2143.

Benachaiba C. and Ferdi,B. 2008. Voltage quality improvement using DVR, Electrical Power Quality and Utilisation Journal, vol. 14, no. 1, pp 39-45.

Benachaiba C., and Ferdi B., 2009. Power quality improvement using DVR. American Journal of Applied Sciences 6 (3): 396-400, 2009 ISSN 1546-9239,pp 396-400

Boonchiam P. and Mithulananthan,N. 2008. Diode-clamped multilevel voltage source converter based on medium voltage DVR, International Journal of Electrical Power and Energy Systems Engineering , pp 62-67.

Chowdary D. D. and Kumar G.V. N., 2008. Restoration of single phase distribution system voltage under fault conditions with DVR using sliding mode control, Indian Journal of Science and Technology, vol.1, no 5,pp 1-5.

Cirrincione M., Pucci M., Vitale G. and Miraoui A., 2009. Current harmonic compensation by a single-phase shunt active power filter controlled by adaptive neural filtering, IEEE Trans. Industrial Electronics, vol. 56, no. 8,pp 3128-3143.

Dixon JW, Venegas G and Mora'n LA., 1997. A series active power filter based on a sinusoidal current-controlled voltage-source inverter, IEEE Trans Industrial Electronics, vol. 44, no.5, pp. 612-620

Ghosh, A. Jindal K., and Joshi,A. 2004. Design of a capacitor-supported dynamic voltage restorer (DVR) for unbalanced and distorted loads, IEEE Trans. Power Delivery, vol. 19, no. 1, pp.405-413.

Ghosh A and . Ledwich G ,2002. Compensation ddistribution systemøltage using DVR, IEEE Trans. Power Delivery, vol. 17, no. 4, pp. 1030-1036

Ghosh A and . Ledwich G., 2002. Power quality enhancement using custom power devices. Kluwer Academic Publishers,

Haque M. T., 2002. Single phase PQ theory for active power filter, Proceedings of IEEE TENCON 02,pp 1941-1944.

IEEE Std. 519-1992, IEEE recommended practices and requirements for harmonic control

Jazayeri M. and Abdollahzadeh H. ,2009. A novel DVR control system design for compensating all types of voltage sags based on pre-fault method, European Journal of Scientific Research ISSN 1450-216X,vol.33, no.1, pp.70-85.

Kumar S. V. R. and Nagaraju S. S., 2007. Simulation of DSTATCOM and DVR in power system, ARPN Journal of Engineering and Applied Sciences, vol. 2, no. 3, pp.7-13.

Khadkikar V., Chandra A. and Singh B. N., 2008. Generalised single-phase p-q theory for active power filtering: simulation and DSP-based experimental investigation, IET Power Electronics ,pp67-78.

Lee G.-M., Lee,D.-C. and Seok J. K., 2004. Control of series active power filters compensating for source voltage unbalance and current harmonics, IEEE Trans. Industrial Electronics , vol. 51, no. 1, pp 132-139.

Morán L. A., Fernández L., Dixon J. W. and Wallace,R. 1997. A simple and $1 \mathrm{ow}-$ cost control s trategy for a ctive power filters connected in cascade, IEEE Trans. Industrial Electronics, vol. 44, no.. 5, pp.621-629.

Mishra KK. and Gupta R., 2009. Harmonic reduction and reactive power compensation in domestic consumer voltage distribution system, Proceedings National Conference, RAEEE-09, NIT, Hamirpur, India, pp.7-11.

Nemati M, H. Yousefian A., and Afshari R., 2009. Recognise the role of a DVR in power systems, International Journal of Recent Trends in Engineering, vol 2, no. 7, pp 13-15.

Omar R. and Rahim N. A., 2010. Design requirements for a dynamic series compensator for voltage sags mitigation in low voltage distribution system, International Conference on Renewable Energies and Power Quality (ICREPQ'10).

Pomilio J. A., and Deckmann S. M., 2007. Characterization and compensation of harmonics and reactive power of residential and commercial loads, IEEE Trans. Power Delivery, vol.22, no.2, pp. 1049-1055.

Peng F. Z., 1998. Application issues of active power filters, IEEE Industry Applications Magazine, pp 21-30.

Ribeiro E. R. and Barbi,I. 2006. Harmonic voltage reduction using a series active filter under different load conditions, IEEE Trans Power Electronics, vol. 21, no. 5, pp 1394-1402.

Singh B., Al-Haddad K., and Chandra,A. 1999. A review of active filters for power quality improvement, IEEE Trans. Ind. Electronics., vol. 46,no. 5, pp. 960-971.

Salmerón. P and Litrán S. P., 2010. Improvement of the electric power quality using series active and shunt passive filters. IEEE Trans. Power Delivary, vol. 25, no. 2, pp.1058-1067.

Salehifar M. and Shoulaie A., "Voltage quality improvement by a series active filter",

Tiwari H. P. and Gupta S. K., 2010. DC energy storage schemes for DVR voltage sag mitigation system, International Journal of Computer Theory and Engineering, vol. 2, no. 3, pp 1793-8201.

Tarnini M.,2009, New series active power filter for computers loads and small non-linear loads, Proceedings of WCECS2009, USA. 


\section{Biographical notes}

Kamala Kant Mishra is an associate professor in Kanpur Institute of Technology, Kanpur (India) and presently pursuing Ph.D. from MN National Institute of Technology, Allahabad (India).He did his graduation in engineering from Institution of Engineers (India) in 1998 and ME with specialization in power system from Punjab Engineering College, Chandigarh (India).in 2004..He has more than 20 years of experience in industry, R \& D and teaching. His area of interest includes power system stability, power quality and application of power electronics to distribution system. He is a member of Institution of Engineers (India).

Dr. Rajesh Gupta, received the B.E. degree from the Madan Mohan Malaviya Engineering College, Gorakhpur, India, in 1993, the M.E. degree from Birla Institute of Technology, Ranchi, India, in 1995, and the Ph.D. degree from the Indian Institute of Technology, Kanpur, India, in 2007, all in electrical engineering. From 1996 to 1999, he was a Lecturer with the Govind Ballabh Pant Engineering College, Pauri Garhwal, India. He is currently an Associate Professor with the Department of Electrical Engineering, M. N. National Institute of Technology, Allahabad, India. His interests include Power Quality, Distributed Generation, Control of Power Electronics based systems and Multilevel Converters. He is a reviewer of many international journals like IEEE Transactions of Industrial Electronics, Power Delivery, IET Power Electronics, International Journal of Power Electronics etc., He is a member of IEEE.

Received January 2011

Accepted March 2011

Final acceptance in revised form April 2011 